\title{
High connectivity among locally adapted populations of a marine fish (Menidia menidia)
}

\author{
Lora M. Clarke, ${ }^{1,3}$ Stephan B. Munch, ${ }^{1}$ Simon R. Thorrold, ${ }^{2}$ and David O. Conover ${ }^{1}$ \\ ${ }^{1}$ School of Marine and Atmospheric Sciences, Stony Brook University, Stony Brook, New York 11794-5000 USA \\ ${ }^{2}$ Biology Department, MS 50, Woods Hole Oceanographic Institution, Woods Hole, Massachusetts 02543 USA
}

\begin{abstract}
Patterns of connectivity are important in understanding the geographic scale of local adaptation in marine populations. While natural selection can lead to local adaptation, high connectivity can diminish the potential for such adaptation to occur. Connectivity, defined as the exchange of individuals among subpopulations, is presumed to be significant in most marine species due to life histories that include widely dispersive stages. However, evidence of local adaptation in marine species, such the Atlantic silverside, Menidia menidia, raises questions concerning the degree of connectivity. We examined geochemical signatures in the otoliths, or ear bones, of adult Atlantic silversides collected in 11 locations along the northeastern coast of the United States from New Jersey to Maine in 2004 and eight locations in 2005 using laser ablation inductively coupled plasma mass spectrometry (ICP-MS) and isotope ratio monitoring mass spectrometry (irm-MS). These signatures were then compared to baseline signatures of juvenile fish of known origin to determine natal origin of these adult fish. We then estimated migration distances and the degree of mixing from these data. In both years, fish generally had the highest probability of originating from the same location in which they were captured $(0.01-0.80)$, but evidence of mixing throughout the sample area was present. Furthermore, adult M. menidia exhibit highly dispersive behavior with some fish migrating over $700 \mathrm{~km}$. The probability of adult fish returning to natal areas differed between years, with the probability being, on average, 0.2 higher in the second year. These findings demonstrate that marine species with largely open populations are capable of local adaptation despite apparently high gene flow.
\end{abstract}

Key words: Atlantic silverside; connectivity; gene flow; local adaptation; Menidia menidia; northeastern U.S. Coast; otolith chemistry; population structure.

\section{INTRODUCTION}

Local adaptation occurs when genotypes in their native habitat have higher relative fitness than genotypes originating from other habitats. Theory suggests that the extent to which local adaptation can occur in a species is dependent on population size, level of gene flow, and selection pressures acting upon each individual (Felenstein 1976, Endler 1977). While natural selection acts as a driving force for local adaptation, gene flow, defined as the movement of alleles among populations, acts as a homogenizing force, and the resulting balance determines the level of adaptation present (Lenormand 2002). The fitness of populations may be reduced in some environments because organismic traits are poorly adapted to local selection processes due to high levels of population mixing and gene flow (Williams 1966).

A number of theoretical studies have examined the role and relative importance of gene flow to local

Manuscript received 26 March 2009; revised 11 March 2010; accepted 19 April 2010. Corresponding Editor: A. L. Shanks.

3 Present address: National Oceanic and Atmospheric Administration, Fisheries, 1315 East-West Highway, Room 15728, Silver Spring, Maryland 20910 USA.

E-mail: Lora.Clarke@noaa.gov adaptation (Felenstein 1976, Slatkin 1987, GarcíaRamos and Kirkpatrick 1997). Empirical studies, while fewer in number, have generally supported Mayr's (1963) conclusion that local adaptation is limited by existing levels of gene flow. Indeed, studies in a range of organisms have shown gene flow to be a constraining force in evolutionary processes (Storfer 1999, Hendry et al. 2002, Postma and van Noordwijk 2005). This evidence, coupled with the widely held notion of high connectivity, may be the reason that relatively few studies have investigated adaptive divergence in marine systems compared to terrestrial systems (but see Stoletzki and Schierwater 2005, Conover et al. 2006).

Measures of population connectivity, defined here as the exchange of individuals among subpopulations (Cowen et al. 2007), are important to our understanding of the geographic scale of local adaptation. In marine organisms, high connectivity and gene flow are often assumed due to life histories that include widely dispersive stages (see review in Swearer et al. 2002, but also see Thorrold et al. 2001, Rooker et al. 2009). However, an increasing number of marine species are now known to display local adaptation across ecological gradients such as latitude (reviewed by Conover et al. 2006, 2009). In such species, the existence of adaptive 
genetic variation raises questions about the relationship between connectivity, gene flow, and the process of adaptation. Is the potential for local adaptation enabled by natal homing or does it exist despite high connectivity because of ongoing selection?

The Atlantic silverside (Menidia menidia) is a marine species in which the existence of local adaptation in a suite of phenotypic traits has been especially well documented (Fig. 1) (Conover and Heins 1987, Conover and Present 1990, Billerbeck et al. 1997). Despite the potential for high dispersal due to an offshore winter migration (Conover and Murawski 1982), substantial evidence of local adaptation exists throughout this species' range, extending along the east coast of North America from northern Florida to the Canadian Maritimes. Local adaptation in M. menidia, is evidenced, for example, by countergradient variation in growth rate (Conover and Present 1990). High-latitude fish have a shorter growing season than low-latitude fish, yet fish across latitudes reach similar sizes at the end of the growing season. A genetic basis for differences in growth rates has been supported in common garden experiments and is likely an adaptation to size-selective winter mortality (Schultz et al. 1998). Additionally, vertebral number (Billerbeck et al. 1997), growth efficiency (Present and Conover 1992), and energy allocation (Billerbeck et al. 2000) covary with growth along a latitudinal gradient. Further evidence of local adaptation in M. menidia involves changes in the level of temperature-dependent sex determination, which varies with latitude in a manner predicted by sex ratio theory (Conover and Heins 1987). The spatial scale of these previous studies investigating local adaptation in $M$. menidia have been on the order of $300-400 \mathrm{~km}$, but strong trait correlations with latitude in these studies suggest that the level of adaptive divergence may exist on an even finer scale (Fig. 1) (Conover and Heins 1987, Conover and Present 1990, Billerbeck et al. 1997). Despite such evidence of local adaptation throughout its range, the degree of connectivity in this species is largely unknown.

Studies of molecular genetic variation that are neutral to selection are one method for detecting gene flow. Recent mitochondrial DNA work has found little evidence of population structuring in M. menidia along the east coast (Mach 2007). A survey of M. menidia from 25 sites along the east coast of North America (Florida, United States, to Prince Edward Island, Canada) showed genetic differentiation occurring only on broad regional scales larger than the scale of adaptation. Genetic techniques examine variation on evolutionary timescales and may not detect population differences that are relevant to the demography of local populations.

A more direct method for estimating connectivity on contemporary timescales may be through the use of otolith chemistry as a natural tag. Recent work using otolith chemistry has demonstrated the ability of

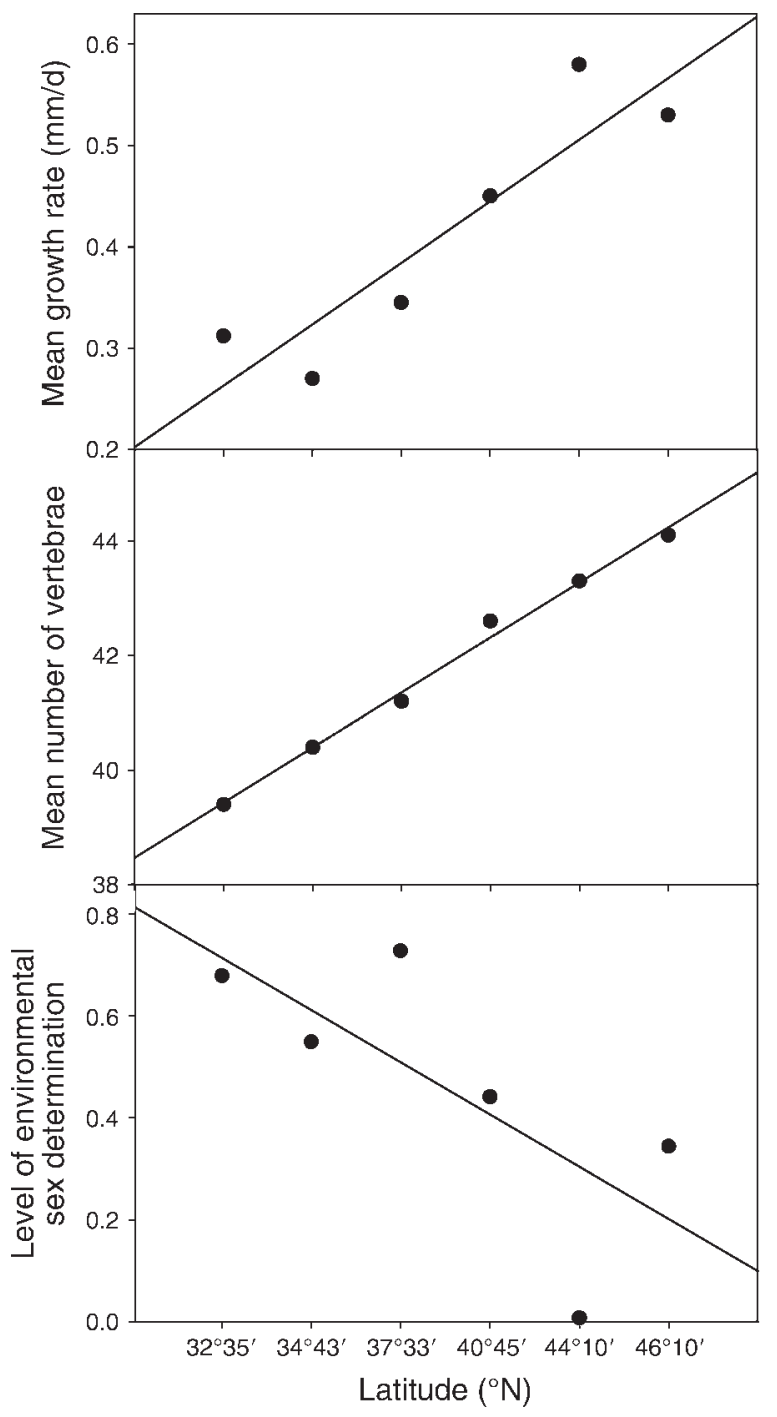

FIG. 1. Evidence of local adaptation in Menidia menidia as evidenced by common-garden experiments. Growth rate $\left(R^{2}=\right.$ $0.88, P<0.05)$, vertebral number $\left(R^{2}=0.99, P<0.001\right)$, and level of environmental sex determination $\left(R^{2}=0.80, P<0.05\right)$ are significantly correlated with latitude. The level of environmental sex determination (ESD) is defined as the proportion of fish with gender determined by temperature within each population. It is estimated by the difference in sex ratio at $15^{\circ} \mathrm{C}$ and $28^{\circ} \mathrm{C}$. Fish eggs were collected in Edisto Bay, South Carolina $\left(32^{\circ} 35^{\prime} \mathrm{N}\right)$; Beaufort, North Carolina $\left(34^{\circ} 43^{\prime} \mathrm{N}\right)$; Upshurs Bay, Virginia $\left(37^{\circ} 33^{\prime}\right.$ N); Great South Bay, New York $\left(40^{\circ} 45^{\prime} \mathrm{N}\right)$; Prince Edward Island, Canada $\left(46^{\circ} 10^{\prime} \mathrm{N}\right)$; and Annapolis River Basin, Nova Scotia, Canada $\left(44^{\circ} 10^{\prime}\right.$ N). Data were taken from Conover and Heins (1987), Conover and Present (1990), and Billerbeck et al. (1997).

otoliths, or ear bones, to reveal population structuring not evidenced by genetic techniques (Thorrold et al. 2001). Otoliths represent natural tags largely due to the manner in which they are formed. Calcium carbonate is laid down in sequential layers, it is not subject to resorption, and otolith growth continues throughout the life of the fish (Thresher 1999). As the otolith forms, 


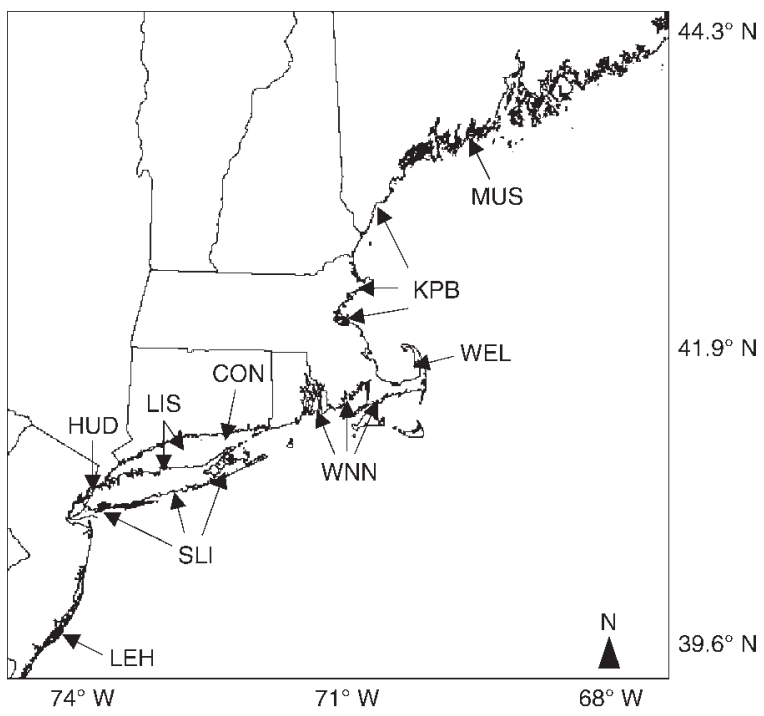

FIG. 2. Map of Menidia menidia sampling locations along the northeastern coast of the United States. See Table 1 for an explanation of abbreviations.

trace elements and stable isotopes are incorporated into its calcium carbonate structure, creating a chemical signature. The elemental and isotopic concentrations detected in otoliths seem to be influenced by one or more factors, such as water chemistry, temperature, diet, and salinity (see review in Campana 1999). In many cases, different natal habitats create distinctive geochemical signatures in otoliths, thus enabling researchers to determine the natal origin of adult fish (e.g., Gillanders and Kingsford 2000) and providing a method to study patterns of connectivity.

This is the first in a series of studies examining the relationship between connectivity, gene flow, and the spatial scale of local adaptation in M. menidia. In this paper, we present otolith chemistry analyses to estimate the level of population connectivity over a large portion of the northern range of the species. Our purpose was to determine whether local adaptation is promoted by natal homing or exists despite high connectivity along the coast. We compare the otolith signatures of spawning adult fish to baseline signatures of juvenile fish of known origin (Clarke et al. 2009) to determine natal origin of these adults. These data allowed us to estimate migration distances and the degree of mixing among subpopulations. Knowledge of connectivity in M. menidia provides an opportunity to elucidate the factors influencing local adaptation in marine systems.

\section{Methods}

\section{Study species}

Menidia menidia is a ubiquitously distributed fish species found in coastal and estuarine waters along the east coast of North America from Florida to the Canadian Maritimes (Conover and Ross 1982). Menidia menidia is a batch spawner, with spawning occurring in the intertidal zone from mid-March through June depending on latitude (Hildebrand 1928). The life history strategy of $M$. menidia promotes minimal dispersal of eggs and larvae in coastal and estuarine habitats (Conover 1982, Griffin and Valiela 2001). Demersal eggs attach to submerged vegetation (Conover 1982), and juveniles remain in their natal estuaries during their first growing season (Griffin and Valiela 2001). In the fall when water temperatures drop, northern populations of $M$. menidia migrate offshore and overwinter on the continental shelf where they presumably mix with conspecifics from numerous inshore habitats (Conover and Murawski 1982). During the winter months, results of bottom trawl surveys showed that the majority of $M$. menidia are found within $\sim 50 \mathrm{~km}$ of the shoreline, but some individuals were captured as far as $170 \mathrm{~km}$ from the coast (Conover and Murawski 1982). In the spring $M$. menidia migrate back into near-shore habitats to spawn. Due to low winter survival, few return to coastal habitats the following spring to spawn. Menidia menidia is essentially an annual species, with most individuals maturing at age 1 and less than $1 \%$ surviving to age 2 (Conover and Ross 1982).

\section{Sample collection}

Ripe adult $M$. menidia were captured in the spring of 2004 from coastal embayments and estuaries using a 30$\mathrm{m}$ beach seine (hereafter referred to as year class 1). All major estuaries were sampled and smaller embayments were randomly selected to fill in distances between these sites and increase the sampling area. Fish were collected from three different sites within each of 11 different locations along the northeastern coast of the United States, ranging from New Jersey to Maine. In the spring of 2005, fish were collected from eight of the same locations, ranging from New York to Massachusetts (hereafter referred to as year class 2; Fig. 2). Ten fish were collected from each of the three sites within the location for a total of 30 fish per location each year. Fish were frozen until otoliths could be processed.

In a previous study, we determined that fish from some locations had to be pooled together to ensure accurate classification of natal origins (Clarke et al. 2009). We determined that there was sufficient chemical heterogeneity to classify $M$. menidia otoliths at a spatial scale of $50-125 \mathrm{~km}$. The 11 locations sampled in year class 1 were pooled together to form seven locations (Table 1, Fig. 2). The eight locations sampled in year class 2 were pooled together to form five locations (Table 1, Fig. 2).

\section{Otolith preparation}

Otolith preparation followed the methods of Clarke et al. (2009). Sagittal otoliths were extracted from fish, cleaned of adhering tissue with Milli-Q ultrapure water (Milli-Q, Billerica, Massachusetts, USA), and air-dried 
TABle 1. Sampling locations for adult and juvenile Menidia menidia.

\begin{tabular}{|c|c|}
\hline Fish sampling locations & $\begin{array}{l}\text { Abbreviation of } \\
\text { pooled location }\end{array}$ \\
\hline \multicolumn{2}{|l|}{ Adult (north to south) } \\
\hline Muscongus Bay, ME & MUS \\
\hline Boston, MA & KPB \\
\hline Waquoit, $\dagger$ MA and Narragansett Bay, $\dagger$ RI & WNN \\
\hline Connecticut River, $\uparrow \mathrm{CT}$ & $\mathrm{CON}$ \\
\hline New Haven $\rightarrow \mathrm{CT}$ and north shore of Long Island, $+\mathrm{NY}$ & LIS \\
\hline Peconic Bay $\uparrow$ NY; Great South Bay, $\uparrow$ NY; and Jamaica Bay, $\uparrow$ NY & SLI \\
\hline Little Egg Harbor, NJ & $\mathrm{LEH}$ \\
\hline \multicolumn{2}{|l|}{ Juvenile (north to south) $\ddagger$} \\
\hline Muscongus Bay, ME & MUS \\
\hline Kittery, ME; Plum Island, MA; and Boston, MA & KPB \\
\hline Wellfleet, MA & WEL \\
\hline Waquoit, $\uparrow$ MA; New Bedford, MA; and Narragansett Bay, $\uparrow$ RI & WNN \\
\hline Connecticut River, $\uparrow$ CT & $\mathrm{CON}$ \\
\hline New Haven $\rightarrow$ CT and North Shore of Long Island $\uparrow$ NY & LIS \\
\hline Peconic Bay, $\uparrow$ NY; Great South Bay, $\uparrow$ NY; and Jamaica Bay, $\uparrow$ NY & SLI \\
\hline Hudson River $†$ NY & HUD \\
\hline Little Egg Harbor, NJ & LEH \\
\hline
\end{tabular}

for $24 \mathrm{~h}$. Otoliths were glued to glass slides and ground to the core using fine-grain lapping paper. One randomly selected otolith from each fish was prepared for trace element analysis and the other for stable isotope analysis. Otoliths for stable isotope analysis were then sealed in individual plastic vials, sealed in plastic bags, and transported to the Micropaleontology Laboratory at the Woods Hole Oceanographic Institution.

A final decontamination for otoliths used in the trace element analysis was conducted under a laminar flow class 100 clean bench. Otoliths were rinsed three times with Milli-Q water, gently scrubbed, rinsed three times with Milli-Q water again, and then sonicated for $2 \mathrm{~min}$. After sonication, otoliths were rinsed once more with Milli-Q water and allowed to dry for $24 \mathrm{~h}$ under the laminar flow hood. Otoliths were then mounted to clean petrographic slides and sealed in plastic Petri dishes, sealed in double plastic bags, and transported to the Woods Hole Oceanographic Institution for analysis using laser ablation inductively coupled plasma mass spectrometry (ICP-MS).

\section{Otolith analysis}

Using a 213-nm laser ablation system coupled to a Thermo Finnigan Element 2 ICP-MS (Thermo Finnigan, Waltham, Massachusetts, USA), we analyzed $\mathrm{Mg}: \mathrm{Ca}, \mathrm{Mn}: \mathrm{Ca}, \mathrm{Cu}: \mathrm{Ca}, \mathrm{Sr}: \mathrm{Ca}, \mathrm{Ba}: \mathrm{Ca}$, and $\mathrm{Pb}: \mathrm{Ca}$ ratios from one randomly selected otolith per fish. Analysis was restricted to a $250 \times 250 \mu \mathrm{m}$ raster centered on the otolith nucleus to ensure only elements deposited during the juvenile life stage of the fish were assayed. Methods for otolith analysis matched those used on otoliths of juvenile $M$. menidia that we had analyzed previously (Clarke et al. 2009). Briefly, the laser traced out a $250 \times$
$250 \mu \mathrm{m}$ raster with $50-\mu \mathrm{m}$ spacing centered on the nucleus of the otolith. We quantified ${ }^{25} \mathrm{Mg},{ }^{43} \mathrm{Ca},{ }^{55} \mathrm{Mn}$, ${ }^{63} \mathrm{Cu},{ }^{86} \mathrm{Sr},{ }^{138} \mathrm{Ba}$, and ${ }^{208} \mathrm{~Pb}$ during each sample run. Detection limits were calculated as three standard deviations of the blanks that were run throughout the analyses. Instrument blanks of $2 \% \mathrm{HNO}_{3}$ were run at the beginning, middle, and end of a block of 10 otoliths and linearly interpolated. A dissolved otolith certified reference material (CRM) (Yoshinaga et al. 2000) was used to correct for instrument mass bias (Rosenthal et al. 1999) and instrument precision was assessed using a second otolith CRM (Sturgeon et al. 2005). Detection limits were calculated as three standard deviations of the blanks that were run throughout the analyses $(n=171)$. These limits were $0.3 \%$ of the average intensity for $\mathrm{Mg}$, $0.1 \%$ for $\mathrm{Ca}, 3.0 \%$ for $\mathrm{Mn}, 17.3 \%$ for $\mathrm{Cu}, 0.01 \%$ for $\mathrm{Sr}$, $0.3 \%$ for $\mathrm{Ba}$, and $10.3 \%$ for $\mathrm{Pb}$. External precisions (relative standard deviations) for the second CRM ( $n=$ 114) were $8.9 \%$ for $\mathrm{Mg}: \mathrm{Ca}, 2.6 \%$ for $\mathrm{Mn}: \mathrm{Ca}, 2.4 \%$ for $\mathrm{Cu}: \mathrm{Ca}, 0.2 \%$ for $\mathrm{Sr}: \mathrm{Ca}, 0.4 \%$ for $\mathrm{Ba}: \mathrm{Ca}$, and $6.3 \%$ for $\mathrm{Pb}: \mathrm{Ca}$.

The matching otolith from each fish was used for stable isotope analysis to determine $\delta^{13} \mathrm{C}$ and $\delta^{18} \mathrm{O}$ signatures. A $250 \times 250 \mu \mathrm{m}$ raster centered on the otolith nucleus was removed at a depth of $90 \mu \mathrm{m}$ using a computer-controlled micromilling system. Otolith material was then weighed, placed in a glass vial, covered with a small amount of methanol, and stored in a drying oven to prepare for analysis. Stable C and O isotopes were measured using a Finnigan MAT253 isotope ratio monitoring mass spectrometer located in the Micropaleontology Laboratory at Woods Hole Oceanographic Institution. Analytical methods followed those outlined by Ostermann and Curry (2000). Isotopic values were 
reported relative to Vienna Pee Dee belemnite (VPDB) and expressed in standard $\delta$ notation. The long-term precision estimate of the mass spectrometer based on analyses of NBS19 is \pm 0.07 for $\delta^{18} \mathrm{O}$ and \pm 0.03 for $\delta^{13} \mathrm{C}$ (Ostermann and Curry 2000).

\section{Statistical analysis}

In a previous study, we determined that juvenile $M$. menidia otolith signatures varied significantly both along the northeastern coast of the United States $(P<0.001)$ and between years $(P<0.001)$ (Clarke et al. 2009). Signatures also appeared to be spatially autocorrelated, as nearby sites were typically more similar than distant sites and results also allowed for otoliths to be classified on a spatial scale of $50-125 \mathrm{~km}$.

Juvenile fish collected from year classes 1 and 2 were assigned to location of capture with $>70 \%$ crossvalidated accuracy using quadratic discriminant function analysis (QDFA) parameterized with the same suite of elemental ratios and stable isotopes analyzed in this study. These juvenile fish belong to the same year class as the adults in the current study, eliminating potential concerns about temporal differences in otolith signatures. We also pooled sites together using the same system to allow for a consistent classification scheme. Site names and pooled group abbreviations are listed in Table 1.

We used a Bayesian approach to determine the origin of adult fish collected at each location. This approach estimates mixed-stock composition for multivariate continuous data and takes into account uncertainty in the juvenile data (Munch and Clarke 2008). It first estimates the site of origin for each individual fish and then estimates the mixing proportions $(\Theta)$ for each site. The mixing proportions are the probability that the individual originates in site $x$ given the individual is caught in location $y$. The Bayesian method assumes equal population sizes for each site. While variability in population size could influence the results, population data are not available for this species. The juvenile data presented in Clarke et al. (2009) were used as the training data to parameterize the method.

One limitation associated with this method, and all other current methods (e.g., QDFA, linear discriminant function analysis, maximum likelihood), is that all samples of unknown origin will be assigned to a location of best fit characterized in the training data, regardless of whether the sample originated from any of the possible locations. Because some of the adult fish in our study are likely originating from locations that we did not sample, we needed to alleviate this problem. One indication of the confidence with which returning adults are classified to a certain location is the Mahalanobis distance. Mahalanobis distances are distances between an individual point (fish) and the centroid for each group (location) normalized by the covariance of the otolith signatures. They can be used as a multivariate outlier statistic. Mahalanobis distances follow a $\chi^{2}$ distribution (Krzanowski 1988). It is unlikely that individuals from our sample area would have a Mahalanobis distance greater than the $\chi^{2}$ critical value $\left(\chi_{0.01,8}^{2}\right)$ of 20.09. Therefore, we chose to list any sample with a Mahalanobis distance greater than 20.09 from a centroid mean as "unclassified."

The probability of migrating a given distance based on location (latitude, longitude) of origin was also determined. Because mixing proportions $(\Theta)$ were not available for every latitude, distances migrated by fish originating from missing locations were interpolated. Actual distances between locations were converted into distances along a "coast-wide" axis by rotating latitude and longitude by $110^{\circ}$. This rotation created the best straight-line approximation to the coast, and we used distances along this line in our calculations. These distances were equivalent to calculating distances along the first principal component of the latitude-longitude matrix. Once these distances were calculated, we were able to determine the probability of migrating a certain distance and direction independent of starting location (Munch and Clarke 2008). The distance probability, $p(D)$, is the probability that an individual is caught at a site a distance $D$ from its site of origin, summed over all starting points.

\section{RESUlTS}

The otolith signatures found in returning adults overlapped with the signatures of the juveniles previously analyzed in Clarke et al. (2009) (Fig. 3). Of the 330 individuals analyzed for year class $1,12.5 \%$ fell into the "unclassified" category (Mahalanobis distance > 20.09), and we assumed that these fish came from locations that were not sampled. A total of $25.0 \%$ of 240 individuals analyzed for year class 2 were similarly assigned as "unclassified."

Individual posterior conditional assignment probabilities demonstrated the certainty with which individuals were classified to a certain location. If the otolith signatures of each population showed complete separation, the assignment probabilities for each individual would be 1 and 0 . While most of the individuals were assigned to a location with a probability of less than 1, the location with the next highest assignment probability was often in one of the nearest sites (Fig. 4). We found a similar pattern in year class 2 , although the result was not immediately clear from Fig. 4 . The coastline in the study region was curved and therefore distances between locations were nonlinear (Fig. 2).

The probability of fish returning to natal locations varied with location. Generally, fish had the highest posterior probability of originating in the location in which they were captured (Fig. 5). For example, fish captured in Muscongus, Maine (MUS), in year class 1 had a posterior probability ranging from 0.15 to 0.5 of originating in Muscongus with a posterior mode of 0.35 (Fig. 5). The posterior probability of fish captured in Muscongus but originating in Wellfleet, Massachusetts 

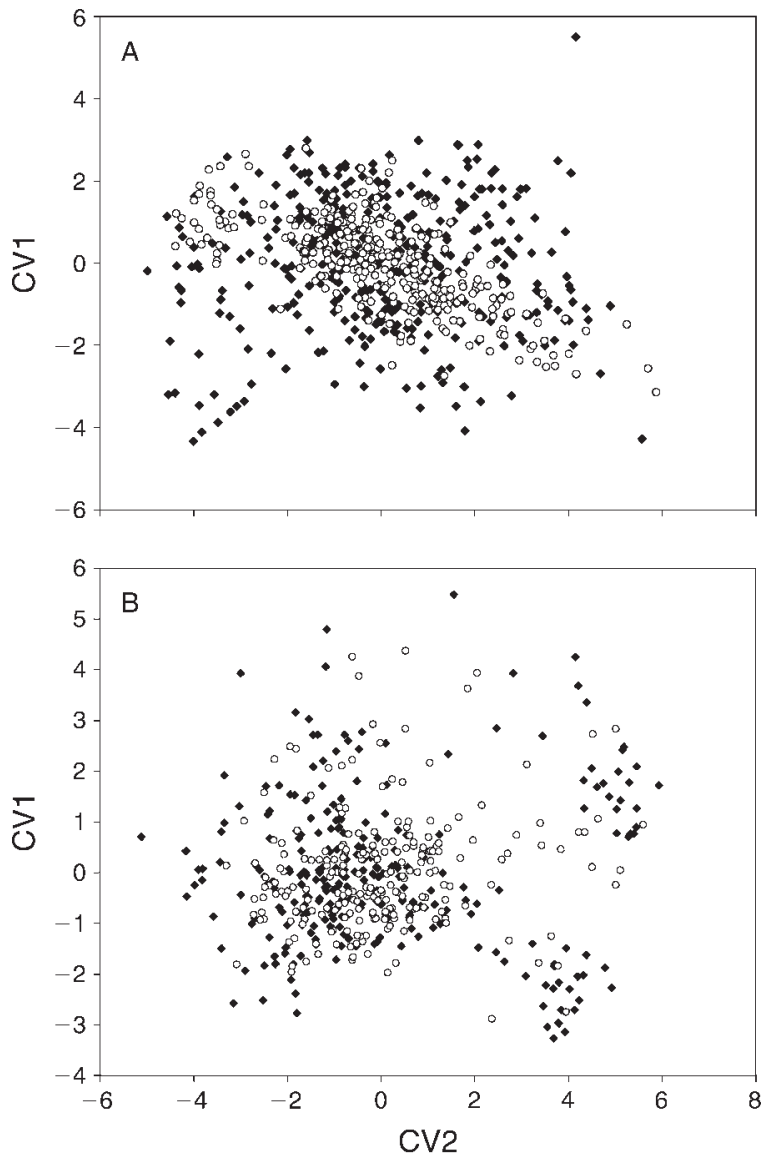

FIG. 3. Comparison of the canonical variates (CV) for (A) year class 1 and (B) year class 2. Juvenile (solid diamonds) and adult (open circles) signatures are shown. Canonical variates were calculated based on $\mathrm{Mg}: \mathrm{Ca}, \mathrm{Mn}: \mathrm{Ca}, \mathrm{Cu}: \mathrm{Ca}, \mathrm{Sr}: \mathrm{Ca}, \mathrm{Ba}: \mathrm{Ca}$, $\mathrm{Pb}: \mathrm{Ca}, \delta^{13} \mathrm{C}$, and $\delta^{18} \mathrm{O}$ otolith values.

(WEL), for example, was $<0.1$. In year class 1 , this trend was true of all sites except the Connecticut River (CON), southern Long Island (SLI), and Little Egg Harbor (LEH). In the Connecticut River, fish had the highest posterior probability of originating from the Hudson River, followed by the Connecticut River and then nearby Long Island Sound (LIS). In SLI and LEH, fish had the highest posterior probability of originating from sites much further away, including north of Cape Cod. While fish had the highest probability of originating from the location of capture at most sites, we also found clear evidence of significant straying from natal estuaries. Trends were similar in year class 2 , with fish having the highest probability of originating from the location of capture, except for LIS fish, which were most likely to originate in SLI. Overall, mixing was widespread among our sample locations, with adults originating in southern locations being detected in northern sample locations and vice versa. Additionally, there was little evidence that fish not returning to their natal site returned to an adjacent site (Fig. 5). Fish that strayed were often originating from some of the locations furthest away from the areas in which they were captured.

The probability of moving a given distance changes based on the location of origin (Fig. 6). In both year classes 1 and 2, fish were more likely to migrate back to the place of origin (represented by the diagonal line in the respective plots), but some anomalies were clear. For example, there was little return back to LEH and south of SLI; instead, these fish had a greater probability of
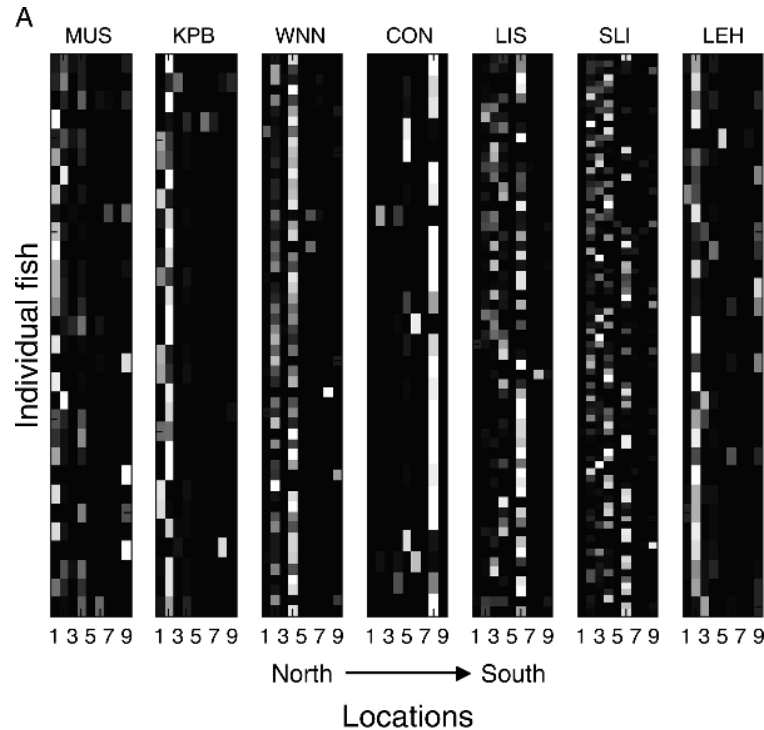

B
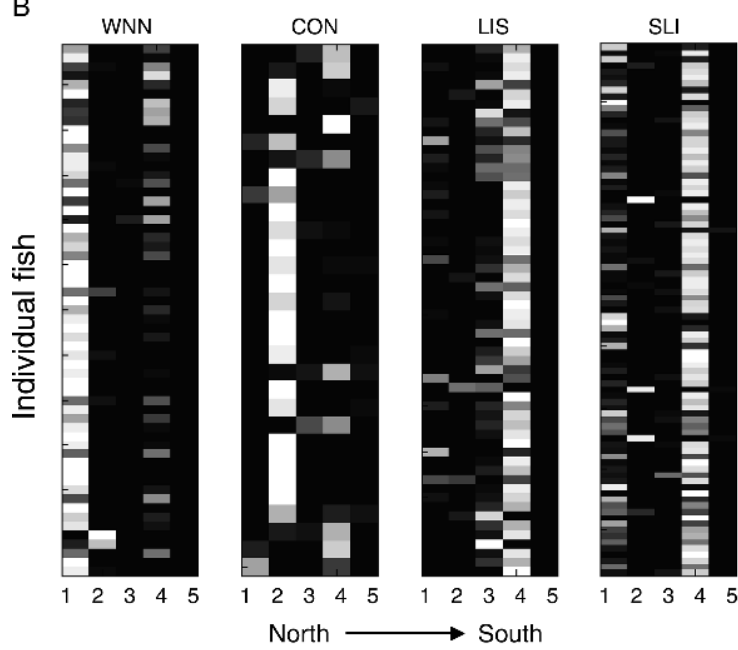

Locations

FIG. 4. Individual posterior classification probabilities for (A) year class 1 and (B) year class 2. Each panel represents all individuals collected at a given site. The columns within each panel indicate possible sites of origin for each individual. Each row indicates the posterior probability for each individual. The gray scale indicates the posterior probabilities ranging from 0 (black) to 1 (white). Possible sites of origin are numbered on the bottom $x$-axis. For year class 1 these are: 1, MUS; 2, KPB; 3 , WEL; 4, WNN; 5, CON; 6, LIS; 7, SLI; 8, HUD; and 9, LEH. For year class 2, these are: $1, \mathrm{WNN} ; 2, \mathrm{CON}$; 3, LIS; 4, SLI; and 5, HUD. See Table 1 for an explanation of abbreviations. 
A

Fish origin

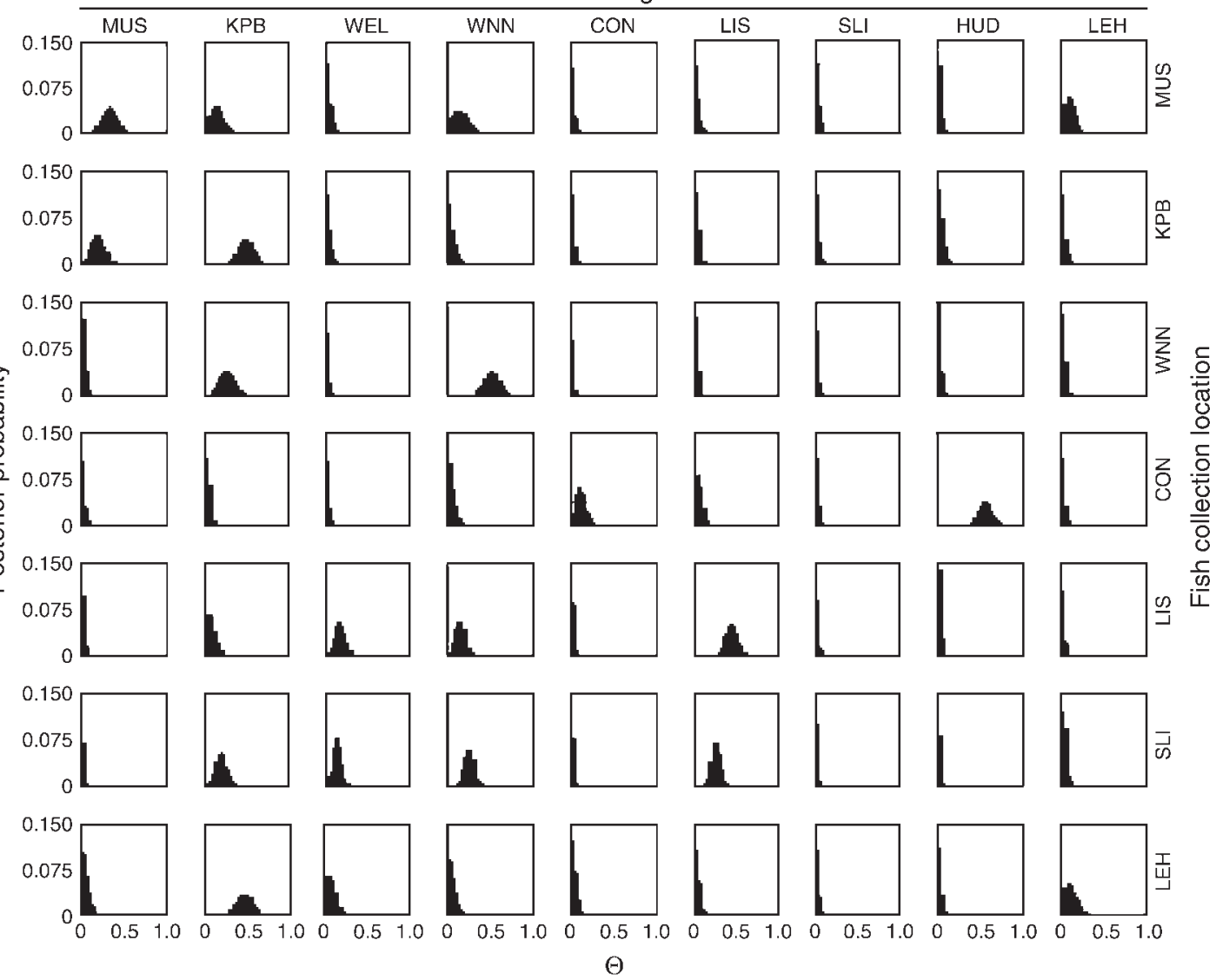

B

Fish origin
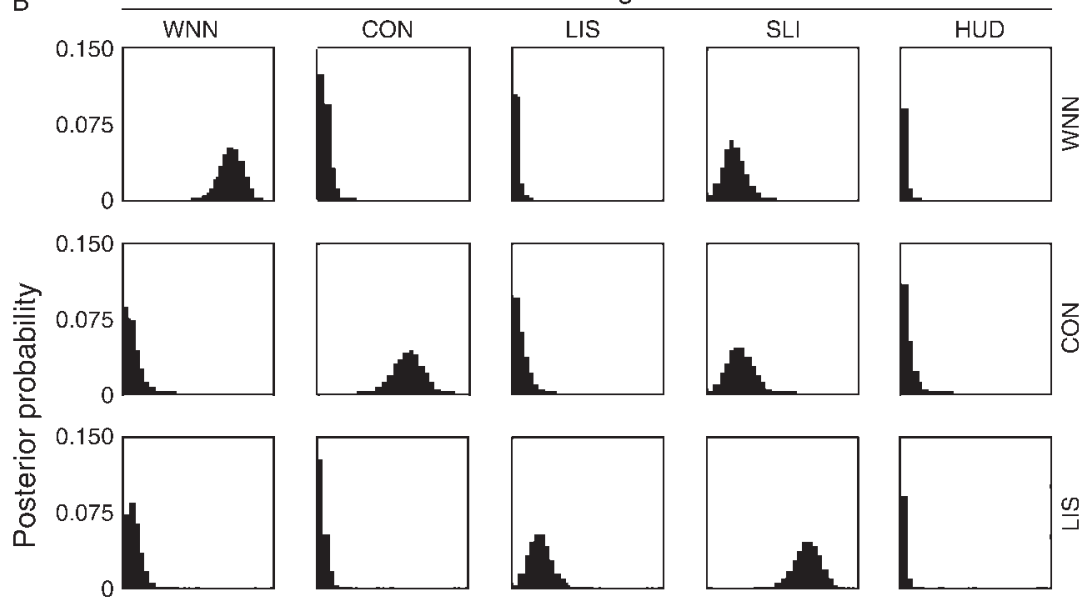

$\sum_{3}^{z}$
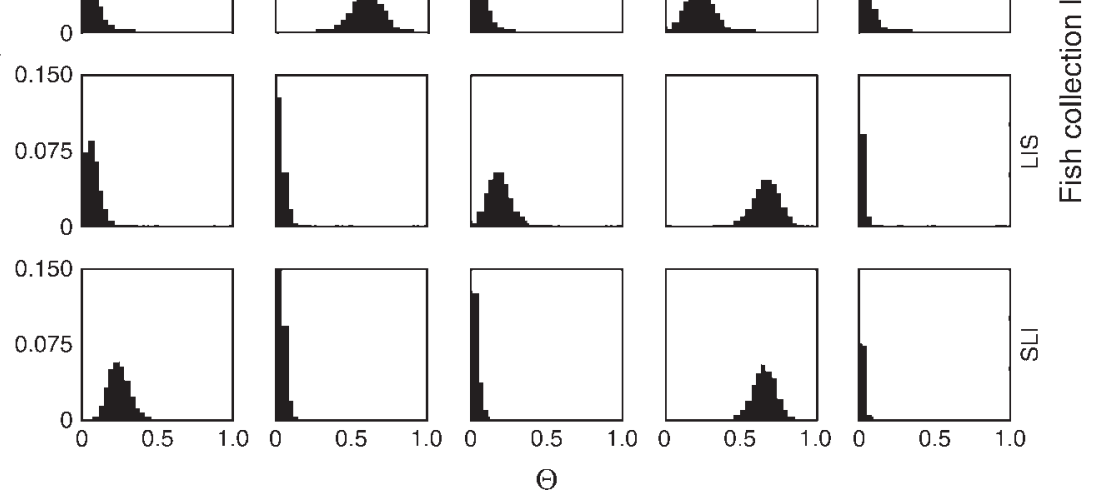

FIG. 5. Posterior probabilities of $\Theta$ for fish in (A) year class 1 and (B) year class 2, where $\Theta$ represents the proportion of fish of certain origin comprising the mixed catch at a location. 
A

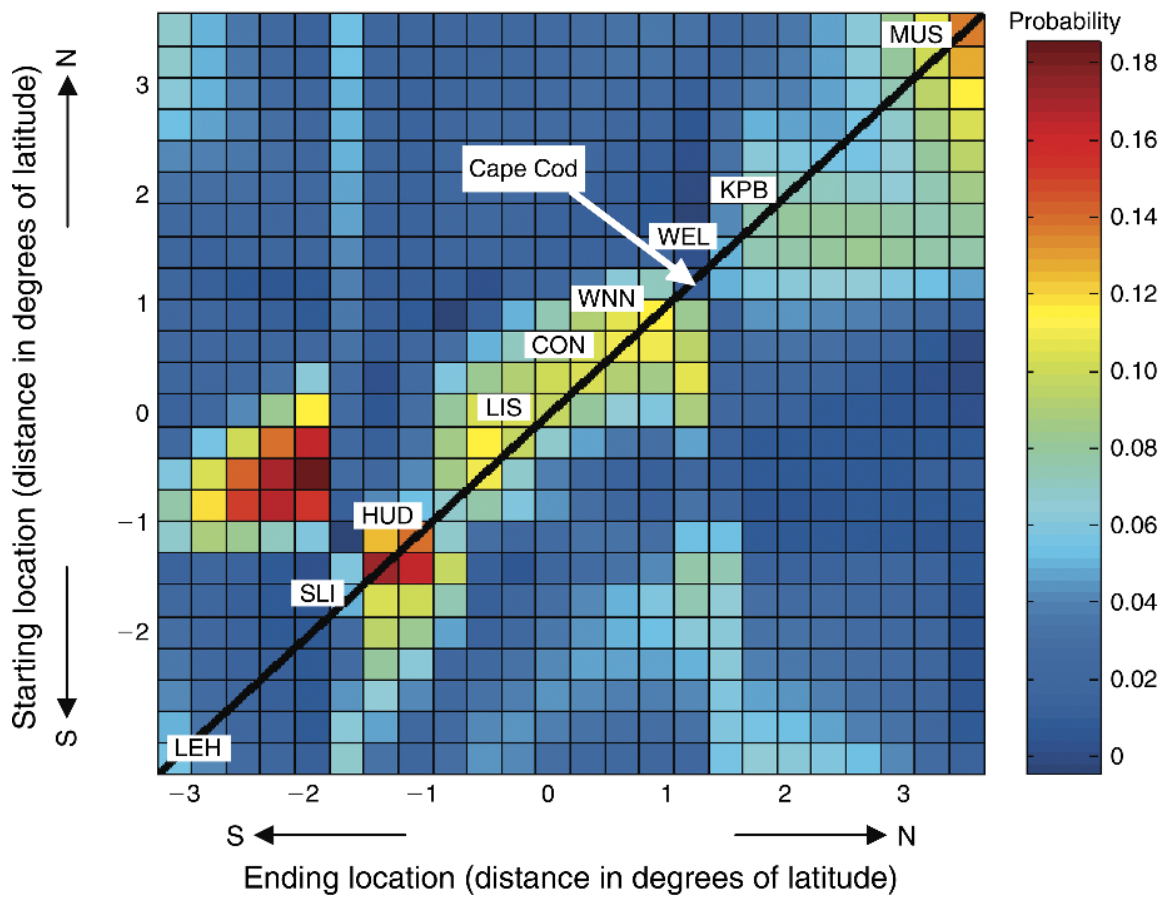

B

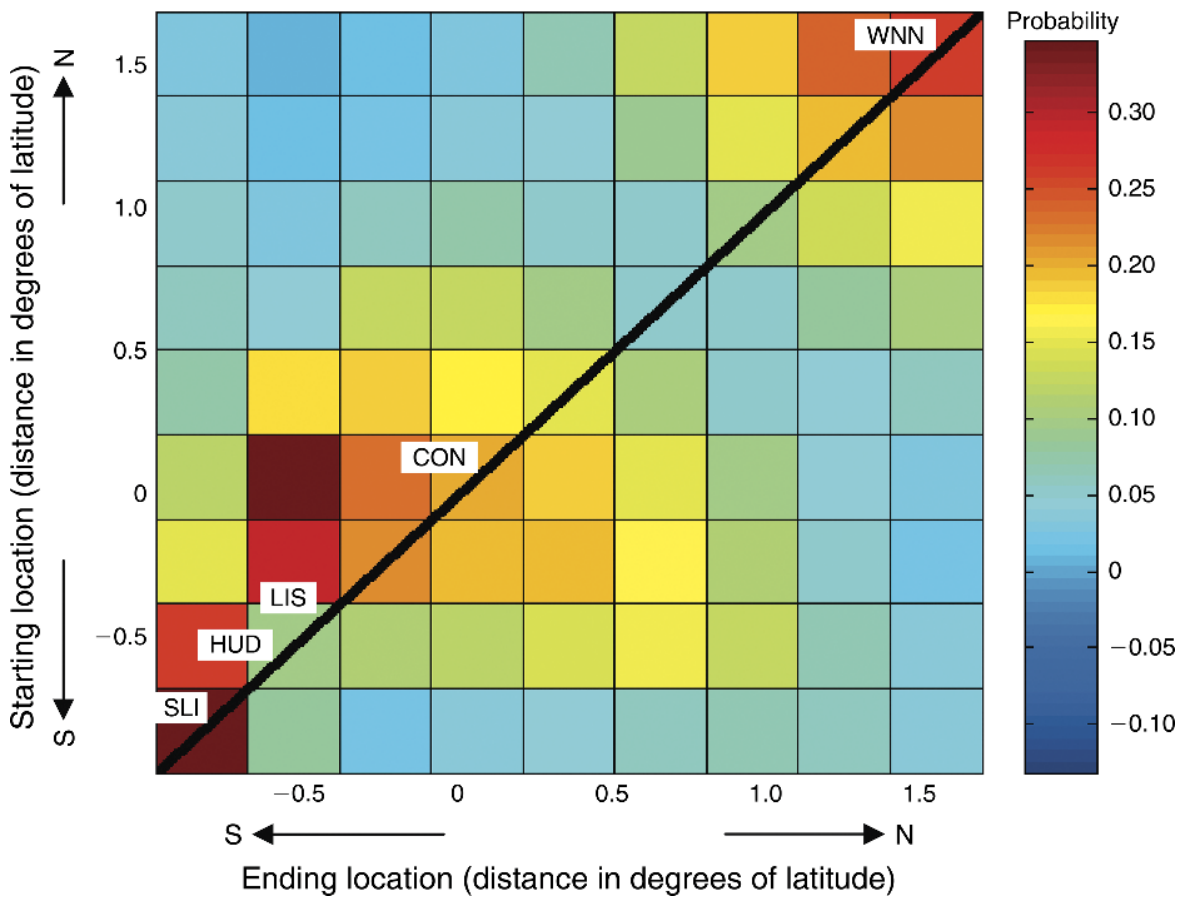

FIG. 6. Probability of migrating a certain distance and direction, given a specific starting location for (A) year class 1 and (B) year class 2 . The diagonal line represents individuals returning to natal locations. North $(\mathrm{N})$ and south $(\mathrm{S})$ directions are indicated. One axis unit ( 0 to 1,1 to 2 , etc.) is equal to $\sim 1^{\circ}$ of latitude $(111 \mathrm{~km})$. Probabilities for distances not available from sampling were interpolated.

migrating north and fish from the northern locations were more likely to migrate to these southern locations. There was also a migration break observed at Cape Cod. Fish from the northern sites (MUS, KPB, and WEL) had the greatest probability of remaining north of Cape Cod and there was relatively low probability of other locations (with the exception of the very southern locations) migrating north of the Cape. In year class 2 , 

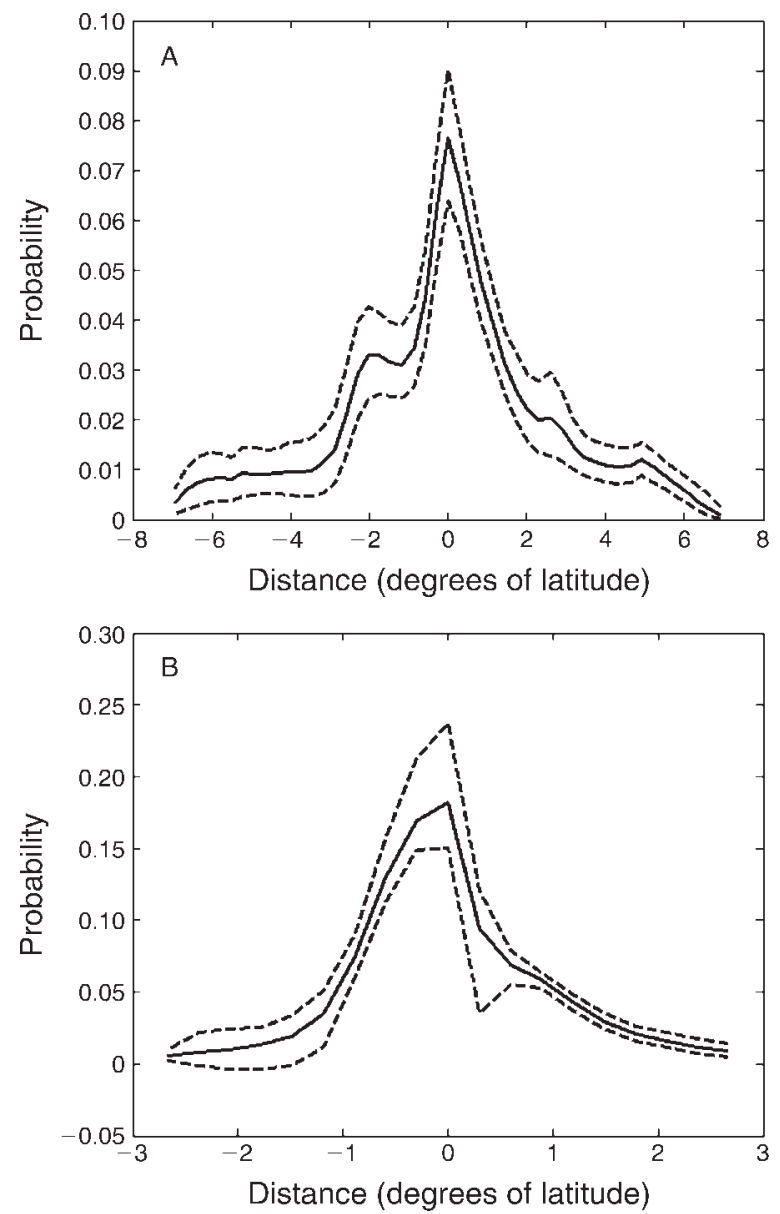

FIG. 7. Probability of migrating a given distance and direction for fish in (A) year class 1 and (B) year class 2 . Distances and direction are independent of starting location. One axis unit ( 0 to 1,1 to 2 , etc.) is equal to $\sim 1^{\circ}$ of latitude (111 $\mathrm{km})$. Negative values represent migration in a southern direction, and positive values represent a northward migration. Dashed lines represent $95 \%$ confidence intervals.

the highest probability was not always found on the diagonal line (representing natal location) but often $50-$ $100 \mathrm{~km}$ away from it. For example, a number of individuals from LIS migrated to CON. There was a slight overall tendency to migrate from north to south.

Fish had the highest probability of migrating within $0-50 \mathrm{~km}$ of their natal site, but migration distances ranged from 0 to over $700 \mathrm{~km}$ in year class 1 . Additionally, there was a bias toward southern migration (Fig. 7). In year class 2, the same shape was observed in the dispersal kernel, but the overall migration distance detected was less due to the smaller spatial scale of sites sampled in that year. Additionally, there was a slight south-north bias, but note the coastline of the sampled area for year 2 has a large west-east gradient.

To ensure that any observed interannual differences in dispersal patterns were simply not the result of the differences in sampling areas between the two years, we also analyzed the data for year class 1 using only the sites that were replicated for year class 2. Results for "reduced" year class 1 were qualitatively the same as the "complete" year class 1, indicating results were not driven by differences in sampling.

\section{DiscusSION}

Menidia menidia shows evidence of local adaptation throughout its range (Fig. 1) (Conover and Heins 1987, Conover and Present 1990, Billerbeck et al. 1997), yet the results of our study showed evidence of connected populations and mixing along the coast. Fish had the highest probability of originating from the location of capture, suggesting natal homing or local retention, but fish also had relatively high probabilities of straying to non-natal sites and migrating distances greater than 200 $\mathrm{km}$. This level of connectivity is surprising given the degree of local adaptation evidenced in this species. Because we do not have measures of outbreeding depression or fate of hybrid offspring, we can only speculate on the level of actual gene flow present. We assume that it is high given that fish collected in this study were ripe and considered to be in spawning condition. Examples of local adaptation in largely open or highly connected environments would suggest that while gene flow may limit the potential for local adaptation to occur, it will rarely prevent it altogether in the presence of strong selection pressures (Schneider et al. 1999, Saint-Laurent et al. 2003).

Theoretical models show that high levels of gene flow can constrain adaptive divergence (Felenstein 1976, Barton and Gale 1993, García-Ramos and Kirkpatrick 1997), and gene flow is often viewed as a constraining force in evolutionary processes (Slatkin 1987). Most existing empirical studies have supported these findings for various taxa across diverse environments (e.g., Storfer 1999, Postma and van Noordwijk 2005). Recent work examining molecular genetic differentiation in $M$. menidia suggests that gene flow along the east coast of the United States is indeed high. An examination of mtDNA variation at 25 sites from Florida, United States, to Prince Edward Island, Canada, revealed very little population structuring and an absence of isolation by distance (Mach 2007). Mach reported only subtle genetic structure in three broad geographic regions (Gulf of St. Lawrence, the Gulf of Maine, and Florida to Cape Cod) and found the pattern consistent in both years of the study. This finding is similar to the conclusions drawn herein and provides further evidence that adaptive divergence exists despite evidence of connectivity and gene flow. It should be noted, however, that low mitochondrial differentiation is not uncommon for temperate marine fish such as $M$. menidia, which may have experienced range expansions following glacial retreats and, thus, may not be representative of high contemporary connectivity.

In many organisms, restricted gene flow can be a result of physical barriers or natal homing (e.g., 
Wheelwright and Mauck 1998, Meylan et al. 1990, Thorrold et al. 2001). We saw some evidence of both in M. menidia. First, our results suggest a break in migration patterns at Cape Cod, a known zoogeographic boundary. This break was also detected in the genetic study by Mach (2007). These findings suggest that the Cape also acts as a physical barrier for $M$. menidia migration, although in this case it seems to diminish migration rather than impede it altogether. Second, evidence of local retention or natal homing was revealed by the observation that fish had the highest probability of originating from the location in which they were captured. Given the long estuarine phase and the high potential for imprinting to occur, we might expect to see a stronger signal if natal homing behavior was common. Alternatively, fish may simply be remaining close to natal areas or are migrating only minimal distances away during winter. This would, in turn, increase the probability of returning to a natal site by chance alone.

In contrast to these findings, natal homing in weakfish (Cynoscion regalis) was shown to be much stronger (60$80 \%$ ), and migrants were largely confined to the next nearest estuary (Thorrold et al. 2001). This pattern was not seen in M. menidia, as migrant fish did not always originate from the next nearest locations. In fact, fish from the northern sites were found in the southern sites and vice versa. This finding also may suggest that mixing is occurring during the overwintering period offshore rather than during the return migration to coastal spawning areas.

Successful immigration of an organism into a new population does not assure reproductive success and, therefore, does not guarantee gene flow between the two populations. Furthermore, selection against migrants can lead to further reductions in gene flow (Bensch et al. 1998, Hendry 2004, Nosil et al. 2005, Bradbury et al. 2008). If selection is strong enough to continually act against immigrant genotypes that are less adapted and, therefore, less fit, genetic divergence can persist (Endler 1977, Schneider et al. 1999, Saint-Laurent et al. 2003). For example, Koehn et al. (1980) demonstrated genetic differentiation exists in the bivalve Mytilus edulis due to differential juvenile mortality. We do not know the reproductive success of the migrants in M. menidia, and it is possible that migrants are less successful than nonmigrants, consequently limiting gene flow. However, we do know that in many of the locations investigated in this study, $>50 \%$ of the catch was composed of migrant fish.

Previous studies investigating the scale of local adaptation in $M$. menidia have been at distances of $300-400 \mathrm{~km}$, but strong trait correlations with latitude in these studies suggest that the level of adaptive divergence exists on a finer scale (Fig. 1) (Conover and Present 1990, Billerbeck et al. 1997). The dispersal range observed in the current study extends further than this $300-\mathrm{km}$ spatial scale, including evidence of movement of reproductively active fish throughout the $\sim 700-\mathrm{km}$ study region. This suggests that strong differential local selection is imposed on finer spatial scales than the level of dispersal and is likely responsible for the clines in adaptive genetic variation. Furthermore, results from common garden experiments on M. menidia drawn from 39 locations along the entire species' range confirm that local adaptation occurs on spatial scales much finer $(<100 \mathrm{~km})$ than that depicted in Fig. 1 and therefore also the scale of connectivity measured here (D. O. Conover, unpublished data).

The proportion of fish from the various locations in samples at each site differed annually. For year class 1, the proportion of fish likely to be returning to natal sites was generally lower than in year class 2 . For example, in 2004, fish captured in the Connecticut River (CON) had a posterior probability mode of 0.1 of originating in CON, but in 2005 this probability increased to 0.6. The locations comprising large proportions of the mixed catch also differed annually. In fact, fish spawned off the coast of southern Long Island comprised very little of the adult catch for any site in 2004, but comprised a greater proportion of the overall catch in 2005. This may suggest differential annual survival in $M$. menidia populations across locations or migration outside of the sampling area.

Menidia menidia undergo an offshore migration in the fall when water temperatures drop (Conover and Ross 1982), and fish can be found as far offshore as $170 \mathrm{~km}$ (Conover and Murawski 1982). In some years, however, fish have been known to stay within nearshore waters. For example, the Connecticut Department of Environmental Protection has reported collecting M. menidia in the Long Island Sound during winter trawl surveys in some years. It is possible that during harsher winters, $M$. menidia migrate further offshore to seek the protection of warmer, deeper waters than in milder winters. Unfortunately, these winter surveys are no longer conducted. Nonetheless, the winter of 2004 was considerably colder than the winter of 2005, possibly explaining the observed yearly differences. The National Oceanic and Atmospheric Administration buoy located $61 \mathrm{~km}$ off the southern shore of Long Island $\left(40^{\circ} 15^{\prime} 1^{\prime \prime}\right.$ $\mathrm{N}, 73^{\circ} 9^{\prime} 59^{\prime \prime} \mathrm{W}$ ) recorded a mean February sea surface temperature of $2.8^{\circ} \mathrm{C}$ in 2004 and $4.5^{\circ} \mathrm{C}$ in 2005 . February was the coldest month for both years. Furthermore, Schultz and Conover (1999) found $>50 \%$ mortality in laboratory experiments examining overwinter energy depletion at $4.0^{\circ} \mathrm{C}$. We speculate that the colder winter of 2004 forced fish further offshore, and therefore, they were less likely to return.

Currents along the northeast coast of the United States flow in a north to south direction, possibly explaining why fish were more likely to migrate southward. Additionally, an individual that migrates southward may have a greater chance of survival than a fish that migrates northward and, therefore, the migration bias could simply represent differential mortality. This north-to-south migration pattern was 
strongest in fish originating north of Cape Cod. The trend was also observed in the year class 2 data, despite the smaller spatial scale of sampling. It should also be noted that we did not sample the entire range of this species and therefore were obviously unable to detect migration outside of the sampling area. For this reason fish at the most northern site (MUS) can only migrate southward or return to their natal site. The opposite is true for fish from the most southern site (LEH). Nonetheless, the southward migration pattern we documented suggests that physical oceanographic features play a role in $M$. menidia migration.

Migration patterns evidenced in this study are the result of otolith chemistry data and interpretation of such information should include the following caveats. A common problem for studies investigating dispersal in marine species is that it is not logistically possible to sample all possible spawning sites and there is a high probability of fish originating from sites not sampled in baseline collections. While this flaw has been recognized by others (Campana et al. 2000, Manel et al. 2002), there has been no progress made in eliminating it. We use Mahalanobis distances as a threshold to determine individuals that are originating from outside the sample area, which helps to alleviate this problem. Moreover, adjacent sites are more similar in chemical signatures than distant sites. Although the existence of this kind of spatial structure in the otolith signatures doesn't exclude the possibility of some fish originating from unsampled sites being misclassified, it does reduce the possibility that fish will be misclassified to distant sites (e.g., "northern" fish classified as "southern" fish and vice versa) and erroneously inflate observed migration distances. In the present analysis, nearby sites are chemically similar so the most likely result will be that spawning locations that are intermediate between our sites will be assigned to the nearest neighbor, which should not generate any bias in the interpolated migration probabilities but will inflate the apparent rates of exchange between our sites. Migration probabilities should be interpreted as transitions among regions rather than specific points on the coastline.

Evidence of connectivity in $M$. menidia from otolith chemistry data suggests that local adaptation is maintained by ongoing contemporary selection pressures. In theory, the previously demonstrated population differences could be due to genetic drift rather than natural selection, although the strong correlations with latitude argue against such an interpretation. The dispersal distances presented here further support the conclusion that genetic drift cannot explain the latitudinal patterns in Fig. 1. One or two migrants per generation can homogenize neutral variation, suggesting population differences in $M$. menidia cannot be neutral and adaptive divergence must be maintained by selective forces. The exact interplay between natural selection and gene flow is not known for $M$. menidia or for any other marine species. Further work is needed to define the spatial scale of adaptive genetic variation (how localized is it?) and to measure the reproductive success of the migrants and selection against immigrant genotypes to gain a more thorough understanding of this evolutionary process.

\section{ACKNOWLEDGMENTS}

This work was funded by the National Science Foundation (grant OCE-0425830 to D. O. Conover and grant OCE0134998 to S. R. Thorrold) and the New York State Department of Environmental Conservation. We thank past and present members of the Conover Laboratory, K. Able, S. Hagan, R. Hagan, and J. Socrates for help with sample collections. We thank V. Barner, T. Duffy, L. Hice, and A. Salvato for help with otolith extractions. We thank S. Birdwhistell and D. Ostermann for assistance with the otolith analyses and S. Sanudo for use of laboratory space. We also thank R. Cerrato and two anonymous reviewers for helpful comments on the manuscript.

\section{Literature Cited}

Barton, N. H., and K. S. Gale. 1993. Genetic analysis of hybrid zones. Pages 13-45 in R. G. Harrison, editor. Hybrid zones and the evolutionary process. Oxford University Press, Oxford, UK.

Bensch, S., D. Hasselquist, B. Nielsen, and B. Hansson. 1998. Higher fitness for philopatric than for immigrant males in a semi-isolated population of great reed warblers. Evolution 52:877-883.

Billerbeck, J. M., G. Orti, and D. O. Conover. 1997. Latitudinal variation in vertebral number has a genetic basis in the Atlantic silverside, Menidia menidia. Canadian Journal of Fisheries and Aquatic Sciences 54:1796-1801.

Billerbeck, J. M., E. T. Schultz, and D. O. Conover. 2000. Adaptive variation in energy acquisition and allocation among latitudinal populations of the Atlantic silverside. Oecologia 122:210-219.

Bradbury, I. R., S. E. Campana, and P. Bentzen. 2008. Otolith elemental composition and adult tagging reveal spawning site fidelity and estuarine dependency in rainbow smelt. Marine Ecology Progress Series 368:255-268.

Campana, S. E. 1999. Chemistry and composition of fish otoliths: pathways, mechanisms and applications. Marine Ecology Progress Series 188:263-297.

Campana, S. E., G. A. Chouinard, J. M. Hanson, A. Frechet, and J. Brattey. 2000. Otolith elemental fingerprints as biological tracers of fish stocks. Fisheries Research 46:343357.

Clarke, L. M., B. D. Walther, S. B. Munch, S. R. Thorrold, and D. O. Conover. 2009. Chemical signatures in the otoliths of a coastal marine fish, Menidia menidia, from the northeastern United States: spatial and temporal differences. Marine Ecology Progress Series 384:261-271.

Conover, D. O. 1982. Seasonal migration, reproductive strategy, and environmental sex determination and its adaptive significance in the Atlantic silverside, Menidia menidia. Dissertation. University of Massachusetts, Amherst, Massachusetts, USA.

Conover, D. O., L. M. Clarke, S. B. Munch, and G. N. Wagner. 2006. Spatial and temporal scales of adaptive divergence in marine fishes and the implications for conservation. Journal of Fish Biology 69:21-47.

Conover, D. O., T. A. Duffy, and L. A. Hice. 2009. The covariance between genetic and environmental influences across ecological gradients: reassessing the evolutionary significance of countergradient and cogradient variation. Annals of the New York Academy of Sciences: the Year in Evolutionary Biology 1168:100-129.

Conover, D. O., and S. W. Heins. 1987. Adaptive variation in environmental and genetic sex determination in a fish. Nature $326: 496-498$. 
Conover, D. O., and S. A. Murawski. 1982. Offshore winter migration of the Atlantic silverside, Menidia menidia. Fishery Bulletin 80:145-150.

Conover, D. O., and T. M. C. Present. 1990. Countergradient variation in growth rate: compensation for length of the growing season among Atlantic silversides from the different latitudes. Oecologia. 83:316-324.

Conover, D. O., and M. R. Ross. 1982. Patterns in seasonal abundance, growth, biomass of the Atlantic silverside, Menidia menidia, in a New England estuary. Estuaries 5: 275-286.

Cowen, R. K., G. Gawarkiewic, P. Pineda, S. R. Thorrold, and F. E. Werner. 2007. Population connectivity in marine systems: an overview. Oceanography 20:14-21.

Endler, J. A. 1977. Geographic variation, speciation, and clines. Princeton University Press, Princeton, New Jersey, USA.

Felenstein, J. 1976. The theoretical population genetics of variable selection and migration. Annual Review of Genetics 10:253-280.

García-Ramos, G., and M. Kirkpatrick. 1997. Genetic models of adaptation and gene flow in peripheral populations. Evolution 51:21-28.

Gillanders, B. M., and M. J. Kingsford. 2000. Elemental fingerprints of otoliths of fish may distinguish estuarine 'nursery' habitats. Marine Ecology Progress Series 201:273286.

Griffin, M. P. A., and I. Valiela. 2001. Delta N-15 isotope studies of life history and trophic position of $F$. heteroclitus and M. menidia. Marine Ecology Progress Series 214:299305.

Hendry, A. P. 2004. Selection against migrants contributes to rapid evolution of ecologically dependent reproductive isolation. Evolutionary Ecology Research 6:1219-1236.

Hendry, A. P., E. B. Taylor, and J. D. McPhail. 2002. Adaptive divergence and the balance between selection and gene flow: lake and stream stickleback in the misty system. Evolution 56:1199-1216.

Hildebrand, W. C. 1928. Fishes of Chesapeake Bay. Bulletin 43. United States Bureau of Fishery, Washington, D.C., USA.

Koehn, R. K., R. I. E Newell, and F. Immermann. 1980. Maintenance of an aminopeptidase allele frequency cline by natural-selection. Proceedings of the National Academy of Sciences USA 77:5385-5389.

Krzanowski, W. J. 1988. Principles of multivariate analysis. Oxford University Press, New York, New York, USA.

Lenormand, T. 2002. Gene flow and the limits to natural selection. Trends in Ecology and Evolution 17:183-189.

Mach, M. 2007. mtDNA variation along pronounced environmental and phenotypic gradients in the estuarine fish, Menidia menidia. Thesis. Boston University, Boston, Massachusetts, USA.

Manel, S., P. Berthier, and G. Luikart. 2002. Detecting wildlife poaching: Identifying the origin of individuals with Bayesian assignment tests and multilocus genotypes. Conservation Biology 16:650-659.

Mayr, E. 1963. Animal species and evolution. Belknap, Cambridge, Massachusetts, USA.

Meylan, A. B., B. W. Bowen, and J. C. Avise. 1990. A genetic test of the natal homing versus social facilitation models for green turtle migration. Science 248:724-727.

Munch, S. B., and L. M. Clarke. 2008. A Bayesian approach to identifying mixtures from otolith chemistry data. Canadian Journal of Fisheries and Aquatic Sciences 65:2742-2751.

Nosil, P., T. H. Vines, and D. J. Funk. 2005. Perspective: reproductive isolation caused by natural selection against immigrants from divergent habitats. Evolution 59:705-719.
Ostermann, D. R., and W. B. Curry. 2000. Calibration of stable isotopic data: an enriched delta O-18 standard used for source gas mixing detection and correction. Paleoceanography $15: 353-360$.

Postma, E., and A. J. van Noordwijk. 2005. Gene flow maintains a large genetic difference in clutch size at small spatial scale. Nature 433:65-68.

Present, T. M. C., and D. O. Conover. 1992. Physiological basis of latitudinal growth differences in Menidia menidia: Variation in consumption or efficiency? Functional Ecology 6:2331.

Rosenthal, Y., P. M. Field, and R. M. Sherrell. 1999. Precise determination of element/calcium ratios in calcareous samples using sector field inductively coupled plasma mass spectrometry. Analytical Chemistry 71:3248-3253.

Saint-Laurent, R., M. Legault, and L. Bernatchez. 2003. Divergent selection maintains adaptive differentiation despite high gene flow between sympatric rainbow smelt ecotypes (Osmerus mordax Mitchill). Molecular Ecology 12:315-330.

Schneider, C. J., T. B. Smith, B. Larison, and C. Moritz. 1999. A test of alternative models of diversification in tropical rainforests: ecological gradients vs. rainforest refugia. Proceedings of the National Academy of Sciences USA 96: 13869-13873.

Schultz, E. T., and D. O. Conover. 1999. The allometry of energy reserve depletion: test of a mechanism for sizedependent winter mortality. Oecologia 119:474-483.

Schultz, E. T., D. O. Conover, and A. Ehtisham. 1998. The dead of winter: size dependent variation and genetic differences in seasonal mortality among Atlantic silverside from different latitudes. Canadian Journal of Fisheries and Aquatic Sciences 55:1149-1157.

Slatkin, M. 1987. Gene flow and the geographic structure of natural populations. Science 236:787-792.

Stoletzki, N., and B. Schierwater. 2005. Genetic and color morph differentiation in the Caribbean sea anemone Condylactis gigantea. Marine Biology 147:747-754.

Storfer, A. 1999. Gene flow and local adaptation in a sunfishsalamander system. Behavorial Ecology and Sociobiology 46: 273-279.

Sturgeon, R. E., S. N. Willie, L. Yang, R. Greenberg, R. O. Spatz, Z. Chen, C. Scriver, V. Clancy, J. W. Lam, and S. Thorrold. 2005. Certification of a fish otolith reference material in support of quality assurance for trace element analysis. Journal of Analytical Atomic Spectrometry 20:167171.

Swearer, S. E., J. S. Shima, M. E. Hellberg, S. R. Thorrold, G. P. Jones, D. R. Robertson, S. G. Morgan, K. A. Selkoe, G. M. Ruiz, and R. R. Warner. 2002. Evidence of selfrecruitment in demersal marine populations. Bulletin of Marine Science 70(Supplement):251-271.

Thorrold, S. R., C. Latkooczy, P. K. Swart, and C. M. Jones. 2001. Natal homing in a marine fish metapopulation. Science 291:297-299.

Thresher, R. E. 1999. Elemental composition of otoliths as a stock delineator in fishes. Fisheries Research 43:165-204.

Wheelwright, N. T., and R. A. Mauck. 1998. Philopatry, natal dispersal, and inbreeding avoidance in an island population of Savannah Sparrows. Ecology 79:755-767.

Williams, G. C. 1966. Adaptation and natural selection. Princeton University Press, Princeton, New Jersey, USA.

Yoshinaga, J., A. Nakama, M. Morita, and J. S. Edmonds. 2000 . Fish otolith reference material for quality assurance of chemical analyses. Marine Chemistry 69:91-97. 